\title{
Sobre as Tentações de Santo Antão: A Forma como as Coisas Significam
}

\author{
On Tentações de Santo Antão: The Way Things Mean
}
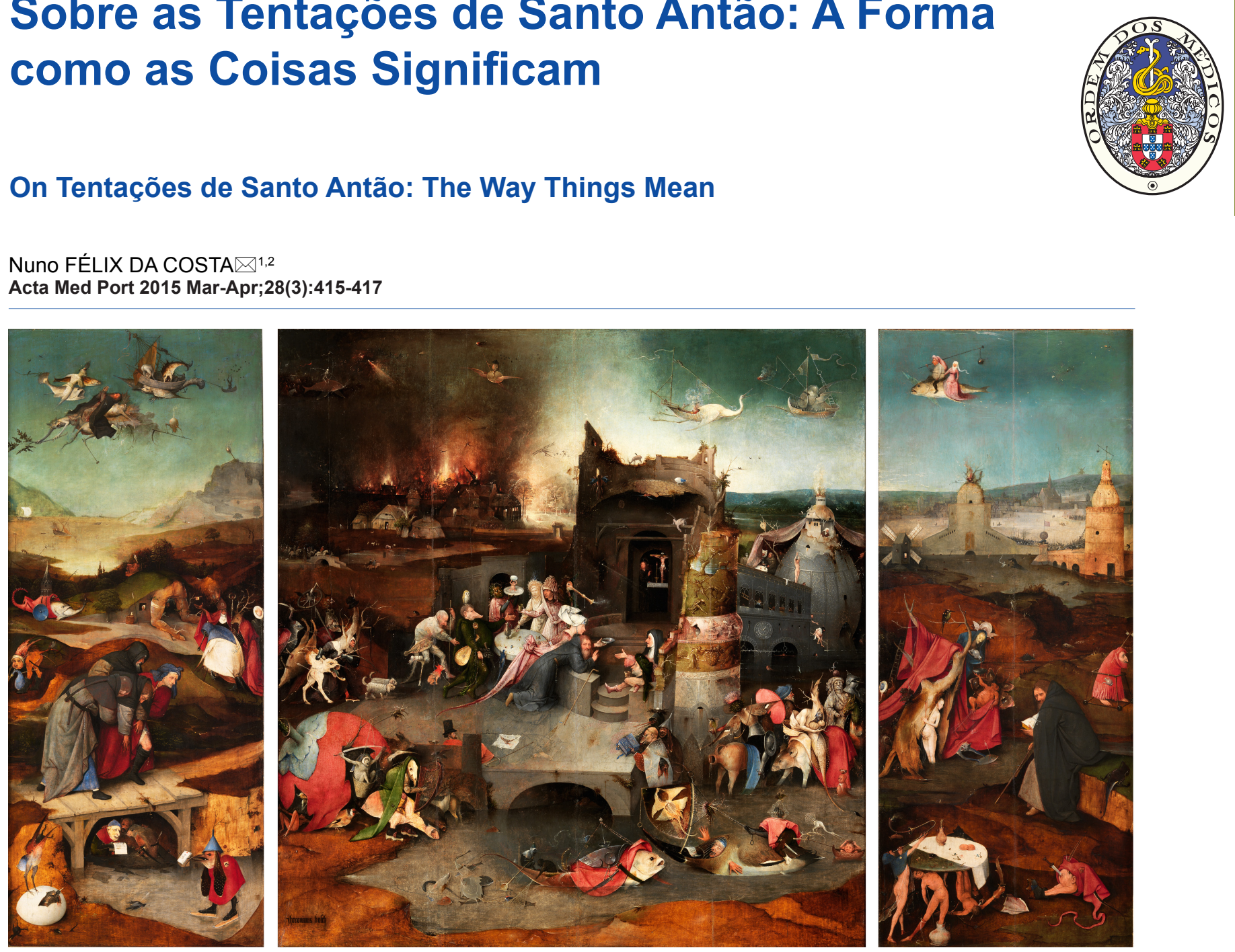

Figura 1 - "Tentações de Santo Antão", Jheronimus Bosch ('s Hertogenbosch 1450/60-1516) c. 1500. Óleo sobre madeira de carvalho. Painel central: $131,5 \times 119 \mathrm{~cm}$, volantes: 131,5 x $53 \mathrm{~cm}$. Proveniência: Palácio das Necessidades, Lisboa, 1913. Museu Nacional de Arte Antiga, inv. 1498 Pint. Fotografia ${ }^{\odot}$ DGPC/ADF/Luisa Oliveira, 2011.

Palavras-chave: Ergotismo; História Medieval; Pintura; Portugal; Religião e Medicina; Santos/história.

Keywords: Ergotism; History, Medieval; Paint; Portugal; Religion and Medicine; Saints/history.

As Tentações de Santo Antão provocam uma pletora de reflexões bastante além da leitura, já de si encantadora, de vívidos conteúdos apologéticos na saída da época medieval. A toada genérica deriva de uma moral cristã de vistas curtas embora um humor grotesco e sarcástico perpasse a visão apocalíptica de uma Europa vista corrompida e caótica. Na verdade, à época assolada por pragas e epidemias variadas e arrasadoras, percebe-se um terreno propício para a emergência de seitas milenaristas e prenúncios do fim do mundo. E contudo, em Itália, o Renascimento surgia com uma visão do mundo otimista e humanista, de certa forma, anunciando uma racionalidade que vingaria no iluminismo e que se tornaria constitutiva da cultura europeia. Mas Jeroen van Aeken, nascido em 1450 numa vila do sul da Holanda, teria uma formação tradicional e confinada mesmo se o seu casamento com a filha de um abastado comerciante local Ihe permitiu uma vida desafogada. Só o mais velho dos irmãos tinha direito a usar profissionalmente o nome de família razão porque Jeroen, além de latinizar o seu nome para Hieronymus, adopta como apelido a partir de 1463 , a terminação do nome da sua vila natal, Hertogenbosh. Vinha de uma família alemã de pintores há três gerações e dos seus cinco irmãos, quatro foram, também, pintores. Ainda assim percebe-se nas suas temáticas uma cosmogonia maniqueísta com uma representação muito dogmática do bem e das vias de salvação de uma malignidade omnipresente, concentrada no demónio e na ideia de inferno, manifestação de uma natureza humana fraca,

\footnotetext{
1. Psiquiatra.

2. Professor de Psicologia Médica. Faculdade de Medicina. Universidade de Lisboa. Lisboa. Portugal.

$\triangle$ Autor correspondente: Nuno Félix da Costa. nunofelixdacosta@gmail.com
}

Recebido: 27 de Janeiro de 2015 - Aceite: 27 de Janeiro de 2015 | Copyright @ Ordem dos Médicos 2015 
precária, mergulhada num universo incompreendido fora deste xadrez teocêntrico.

Remonta a Zoroastro (1500 a.C.) a concepção da linha do tempo como sujeita a interrupções ditadas pela corrupção do seu funcionamento e visando um restabelecimento glorioso mercê de alguma forma de intervenção sobrenatural redentora. Esta concepção não completamente linear do tempo influenciou todos os monoteísmos. Na cultura cristã, o Apocalipse foi escrito por S. João em Patmos e, de certa forma, alimentou uma linha de pensamento dentro do Cristianismo que, se se atenuou no Catolicismo, persiste em várias Igrejas Evangélicas e nas Testemunhas de Jeová. A Igreja nos tempos de Bosch saíra da crise dos papas de Avignon desvirtuada dos seus propósitos, mais ligada ao poder político e à acumulação de riqueza. Esta situação contribuiu para revoltas populares que, de alguma forma, se afiliavam neste pensamento milenarista - os taboritas, na Boémia, o próprio Lutero - todas elas eivadas por uma atitude crítica em relação à Igreja e pregando a necessidade da sua reforma. Esta problemática da degradação dos valores que alicerçam a cultura europeia reaparece, hoje, com grande premência: podemos ler o iluminismo como um processo iniciado com a Revolução Francesa que levou a Europa a redefinir-se como um espaço laico marcado pela Declaração Universal dos Direitos do Homem e pelas respetivas liberdades e direitos fundamentais assim sustidos fora de um referencial religioso. Posteriormente, o desenvolvimento da economia no sentido do capitalismo e da sociedade de mercado levou a um domínio dos valores do consumo e do individualismo que também desvirtuaram o próprio sentido do humanismo europeu, tornado, assim, subsidiário de um mercantilismo alienante, mas que se revelou muito aliciante e intrusivo não só no Ocidente, mas em toda a contemporaneidade.

O setor da saúde não escapou a esta tendência; o médico, assoberbado na sua profissão, tende a perder a distância em relação às condições da sua prática e à medida em que ela é tomada por valores estranhos a uma noção de saúde que deveria fomentar o crescimento individual e uma vida em harmonia com os sistemas ecológicos. E, contudo, a sua responsabilidade decorrente da deontologia hipocrática é clara em não restringir a intervenção médica ao alívio sintomático e à restituição da saúde física do seu doente. Se uma função salvífica como a prescrita pela definição de saúde da Organização Mundial de Saúde está, claramente, além do seu efetivo poder, a representação mental do médico na sociedade confere-lhe ainda uma capacidade de intervenção junto do seu doente que seria melhor utilizada nesta linha do que a alimentar o consumo desproporcionado de medicamentos. Mas vivemos numa época de grandes contrastes conceptuais ao contrário da época medieval onde ainda a obra de Bosch se inscreve; ou talvez que esses contrastes se tenham tornado hoje, apenas mais matizados. Nas Tentações de Santo Antão distinguimos facilmente entre o Bem e o Mal, são fáceis de definir e representar, enquanto a cultura pós-moderna se carateriza pela pluralidade de referências num quadro de múltiplas pertenças e de tolerância para com diversos modelos de identidade. A noção de Bem, se ainda pode incluir alguns critérios positivos como a mencionada tolerância e o respeito democrático pelos direitos dos outros, a generosidade e a solidariedade social, a paz e o respeito por alguma harmonia ecológica, define-se, sobretudo, por interdições e ilicitudes. É neste sentido que a fricção entre a cultura cristã e a cultura islâmica que em si e historicamente não são substancialmente incompatíveis, evoluíram para atitudes opostas face à contemporaneidade pós-industrial, sentidas por alguns como irreconciliáveis e ameaçadoras.

O tríptico pintado em 1501, integra ainda no verso dos dois painéis laterais, visíveis quando cerrado, duas pinturas monocromáticas representando cenas da crucificação e da paixão de Jesus Cristo numa atmosfera desolada e plana, mas, aqui, ainda as personagens são os paisanos contemporâneos do pintor e não se suspeita do que o tríptico aberto revela: a ocupação do espaço da tela lembra uma grande produção cinematográfica hollywoodesca no sentido de incluir diferentes planos e diferentes tempos numa narrativa que parece pretender obter efeitos moralizadores nos seus espetadores tal como acontece, frequentemente, no grande cinema americano. Ausente a dimensão temporal que carateriza a narrativa do cinema, assistimos a uma concatenação de diversas cenas das Tentações de Santo Antão no mesmo espaço e no mesmo tempo. Este santo eremita egípcio, nascido em 251 viveu, no deserto, a imitação do jejum de Cristo. No painel esquerdo, vemo-lo ladeado por um monge e por uma figura identificada com o próprio pintor que amparam a caminhada do santo. $O$ auto-retrato na pintura é relativamente frequente bem como a figuração das personagens religiosas com o rosto dos patronos que encomendaram a obra. Trata-se de satisfazer o narcisismo de quem tem o poder de representar ou de se fazer representar e, embora existam manifestações desta tendência desde a pintura rupestre como as palmas da mão impressas na parede da gruta, é a partir do Renascimento que se torna frequente na pintura europeia. Rembrandt, por exemplo terá pintado mais de cinquenta auto-retratos ao longo da vida e recordamos como nas Meninas, Velásquez recorre a um subtil artifício para se incluir no espaço da tela. No painel direito vemos algumas das tentações a que o santo foi sujeito: a sedução por uma mulher nua que o alicia; o santo desvia o olhar, mas logo encontra, num primeiro plano, a oferta de opíparos manjares. A entrada para o que é interpretado como um prostíbulo no painel da esquerda é feita entre as pernas de um homem de gatas. Estas alusões a práticas sexuais tidas como pecaminosas, a própria posição do homem em prece maometana, lembra quanto Santo Antão, um dos primeiros e mais influentes dos padres anacoretas, se tornou na Europa medieval o protetor de numerosas doenças infecciosas como a sífilis e a erisipela gangrenosa tendo inspirado, a formação de uma ordem monástica dedicada ao tratamento dos doentes a qual, desde o reinado de D. Sancho II, chegou a ter conventos em Portugal e ainda hoje persistem inúmeros locais de culto a Santo Antão. 
A obra terá sido adquirida por Damião de Góis junto com uma outra para a sua coleção particular na primeira metade do século XVI. Aparece reportada na coleção real portuguesa no século XIX e é oferecida ao Museu de Arte Antiga pelo último rei. Comparativamente com outras potências europeias, Portugal, desde o século quinze envolvido em projetos fora de portas em todos os continentes, alguns bastante lucrativos, não acumulou uma riqueza proporcional. Com a exceção do convento de Mafra, a arquitetura portuguesa, embora graciosa, guarda uma escala modesta e não encontramos nos museus portugueses os tesouros que imaginamos como se os valores artísticos e culturais fossem menosprezados a favor de propósitos comerciais de agentes de escassa cultura. Damião de Góis, neste sentido, é uma personagem excecional. Educado na corte, era da mesma idade e companheiro de infância do futuro rei D. João III que o envia para Antuérpia, trabalhar na feitoria que negociava a venda dos produtos do oriente com os comerciantes flamengos. Tornou-se um rico cidadão cosmopolita, amante da boa vida, mas também das artes e ativamente empenhado nas questões da época. De resto, foram as suas opiniões heterodoxas que levaram à sua condenação a prisão perpétua pela Inquisição e ao seu provável assassinato. O país nunca tratou bem os seus melhores, tarda em lhes reconhecer os méritos e só nas suas obras póstumas a sua presença é enaltecida. Em Espanha, Filipe IV conferiria inúmeros poderes a Diego Velásquez, não só como pintor da corte, também no que toca à gestão da decoração dos palácios reais; muitas das obras que integram a coleção do Prado foram por ele adquiridas. Não existe nada de comparável na pintura portuguesa antiga com exceção dos painéis de S. Vicente de Fora de 1445 que apenas em 1822 foram acidentalmente reconhecidos por Columbano, muito maltratados no Paço do Patriarca. Tinham sido sujeitos a inúmeras intervenções e repinturas e tiveram que esperar quase quatro séculos para serem consideradas como um pilar único na pintura portuguesa.

O ergotismo ou Fogo de Santo Antão é uma infeção provocada por um fungo que se desenvolve na cravagem do centeio e noutros cereais menos frequentemente. $O$ fungo produz ergotamina entre outras substâncias, a qual é aparentada com o LSD, um potente alucinogéneo. Muitas das figuras do tríptico têm um aspeto monstruoso que resulta da sua natureza híbrida meio humana meio animal Esta contaminação de conceitos, a interpenetração de um pelo outro como se fossem indistintos os seus limites ou variassem ao sabor do devaneio, é um mecanismo de distorção do real frequente em psicoses como a esquizofrenia ou em psicoses tóxicas como as viagens provocadas pelos alucinogéneos. É interessante como, nesta obra, Bosch entrecruza diversos níveis de significação e, correlativamente, diversos níveis de leitura. Até o incêndio numa cidade, ao fundo no painel central do tríptico, pode ter um valor de trauma e corresponder a uma memória de infância: o autor teria treze anos quando um fogo destruiu 4000 casas na sua cidade. Imaginamos o seu terror quando faz reaparecer essa memória dramática como efeito apocalíptico de expiação da corrupção do mundo pelo pecado.

\section{AGRADECIMENTOS}

A Acta Médica Portuguesa e a Ordem dos Médicos agradecem ao Museu Nacional de Arte Antiga em Lisboa a gentil cedência dos direitos de reprodução deste quadro e a oportunidade de o divulgar.

\section{CONFLITOS DE INTERESSE}

$\mathrm{O}$ autor nega qualquer conflito de interesses.

\section{FONTES DE FINANCIAMENTO}

O autor não recebeu nenhum financiamento para a escrita do artigo. 


\section{Nuno FÉLIX DA COSTA \\ Sobre as Tentações de Santo Antão: A Forma como as Coisas Significam}

Acta Med Port 2015:28:415-417

Publicado pela Acta Médica Portuguesa, a Revista Científica da Ordem dos Médicos

Av. Almirante Gago Coutinho, 151

1749-084 Lisboa, Portugal.

Tel: +351218428 215

E-mail: submissao@actamedicaportuguesa.com

www.actamedicaportuguesa.com

ISSN:0870-399X | e-ISSN: 1646-0758

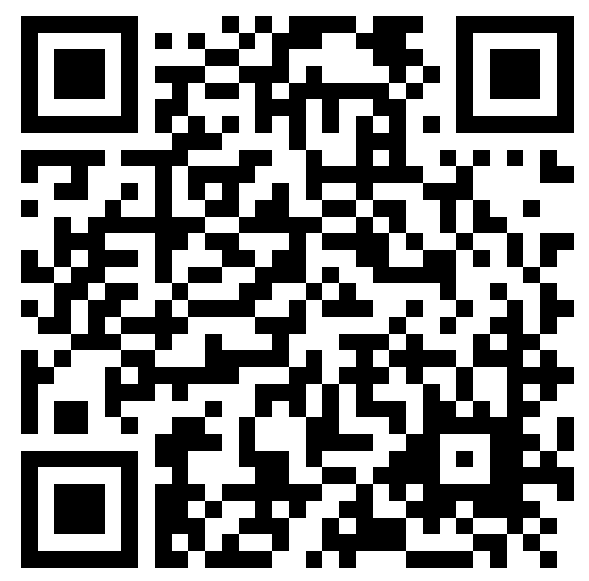

